\title{
Autism Spectrum Disorder Updates - Relevant Information for Early Interventionists to Consider
}

\author{
Paula Allen-Meares ${ }^{1}$, Megan MacDonald ${ }^{2 *}$ and Kristin $\mathrm{McGee}^{3}$ \\ ${ }^{1}$ University of Illinois at Chicago, Chicago, IL, USA, ${ }^{2}$ College of Public Health and Human Sciences, Oregon State University, \\ Corvallis, OR, USA, ${ }^{3}$ Emerson Waldorf School, Chapel Hill, NC, USA
}

\section{OPEN ACCESS}

Edited by:

Hatim A. Omar,

University of Kentucky, USA

Reviewed by:

Lokesh Tiwari,

All India Institute of Medical

Sciences Patna, India

Mandakini Sadhir,

University of Kentucky, USA

Alissa Briggs,

University of Kentucky, USA

${ }^{*}$ Correspondence:

Megan MacDonald

megan.macdonald@oregonstate.edu

Specialty section: This article was submitted to Child Health and Human Development, a section of the journal

Frontiers in Public Health

Received: 30 August 2016 Accepted: 07 October 2016 Published: 28 October 2016

Citation:

Allen-Meares $P$, MacDonald M and McGee K (2016) Autism

Spectrum Disorder Updates -

Relevant Information for Early Interventionists to Consider.

Front. Public Health 4:236. doi: 10.3389/fpubh.2016.00236
Autism spectrum disorder (ASD) is a pervasive developmental disorder characterized by deficits in social communication skills as well as repetitive, restricted or stereotyped behaviors (1). Early interventionists are often found at the forefront of assessment, evaluation, and early intervention services for children with ASD. The role of an early intervention specialist may include assessing developmental history, providing group and individual counseling, working in partnership with families on home, school, and community environments, mobilizing school and community resources, and assisting in the development of positive early intervention strategies $(2,3)$. The commonality among these roles resides in the importance of providing up-to-date, relevant information to families and children. The purpose of this review is to provide pertinent up-to-date knowledge for early interventionists to help inform practice in working with individuals with ASD, including common behavioral models of intervention.

\section{Keywords: ASD, early intervention}

Public awareness about autism spectrum disorder (henceforth autism or ASD) is growing rapidly as prevalence statistics estimate that 1 in 64 children are diagnosed with autism (4). This means more than a 10-fold increase in prevalence since the 1980s (5). With ASD rates climbing across racial, ethnic, and socio-economic groups, ASD continues to hold the public's attention as the most common childhood neurodevelopmental disorder (6). Fortunately, up-to-date research is at our fingertips, as the field refines its knowledge about ASD, it is imperative for early interventionists to stay informed about the most current information and best practices, as they relate to early intervention. The purpose of this review is to provide pertinent up-to-date knowledge for clinicians to help inform practice about early intervention and related knowledge.

Autism spectrum disorder is a complex neurodevelopmental disorder that typically presents during toddlerhood $(7,8)$. The hallmark characteristics of ASD are deficits in social communication skills as well as repetitive, restricted, or stereotypical behavior (1). For example, children with ASD may have difficulty with reciprocal social interaction, joint attention, social initiations, gestures, using body language for non-verbal communication, appropriate facial expressions and eye contact $(9,10)$. Individuals with ASD may also display repetitive and restricted behaviors. These behaviors are broad but might look like a preoccupation with a specific interest, adherence to a specific routine and repetitive non-functional movements (11). For example, in young children, hand-flapping (stereotypical behavior) or lining up toys (repetitive/restrictive behavior) would characterize such behaviors. In older children with ASD, a preoccupation with a particular television show, animal, or topic of interest would be considered a restrictive behavior. Although we all have our own unique interests, in this context the preoccupation characteristically restricts the child from traditional social 
interactions, and interrupts daily living routines. For example, it might be difficult to have a conversation without the child bringing the conversation back to their own preoccupied interest or, when a child is hand-flapping he or she may not be focused on learning the task at hand.

The previous iteration of the Diagnostic and Statistical Manual of Mental Disorders, Fourth Edition (12), used pervasive developmental disorder (PDD) as the umbrella term for five unique diagnoses - autistic disorder, Asperger's disorder, Rett's disorder, childhood disintegrative disorder (CDD), and PDD - Not Otherwise Specified (PDD-NOS), all of which share deficits in social communication skills as well as a limited range of repetitive or stereotyped activities and interests. The most current edition of the Diagnostic and Statistical Manual of Mental Disorders, Fifth Edition (1) is more focused on one diagnosis of ASD - this restructure from previous iterations of the DSM was focused on commonalities of the unique diagnoses mentioned above $(1,13)$. Although DSM-IV terminology lingers (e.g., Asperger's syndrome), it is important to consider the new diagnostic criteria in practice. In other words, similarities in respect to the core characteristics of ASD are routed in early intervention services, yet these characteristics will differ significantly by each individual.

Other comorbid disorders commonly associated with ASD may include, Attention Deficit Hyperactivity Disorder (hyperactivity, short attention span, impulsivity), aggressive behaviors, tantrums, self-injury, chronic sleep problems, atypical eating patterns, over-responsiveness or under-responsiveness to sensory stimulation, and affective difficulties (depression, anxiety) (14). Although these behaviors are common, they are not exclusive to individuals with ASD, nor are they necessary for a diagnosis of ASD.

\section{ETIOLOGY}

Researchers and clinicians are working collaboratively and around-the-clock to better understand the etiology of ASD. While there is evidence to suggest genetic underpinnings of ASD, there is no known specific cause of ASD (15-17). While ASD prevalence is higher among boys than girls, it has not been shown to be more prevalent among specific racial, ethnic, or socio-economic groups. Furthermore, while ASD has been primarily considered a neurodevelopmental disorder, there is growing evidence that ASD impacts multiple whole body systems (18). Although an in-depth discussion of the possible etiology of ASD is beyond the scope of this article, we would highly encourage follow-up with recent reviews focused on the following cause theories: genetics $(16,17,19)$, environment (18), and obstetric complications and systemizing theory (20).

\section{DIAGNOSIS}

\section{Importance of Early Diagnosis}

Parents of children with ASD tend to notice abnormalities during the child's first 2 years and many parents notice the first signs of abnormal development before the child's first birthday (21). The most common concerns are delays in speech and language development $(8,22)$ followed by abnormal social responsiveness, medical problems, difficulties sleeping and eating, delays reaching milestones, abnormal developmental trajectories, and developmental regression (21, 23-26). The American Academy of Pediatrics (AAP) has recommended universal ASD screening for all young children twice before their second birthday (27). However, in practice the AAP recommendations are not always followed and many children are not diagnosed before age five (28). The importance of early diagnosis is gaining momentum within the ASD community, especially as the understanding of how the disorder presents at younger ages grows (29). Clinically observed behavioral markers of ASD have been recognized well before 24 months of age (30) and more recent findings support reliable diagnosis as young as 12 months of age $(7,31)$. In essence, early diagnosis leads to earlier eligibility for intervention services, and evidence-based research has clearly indicated that early intervention leads to better prognosis $(9,32-34)$.

\section{SCREENING AND ASSESSMENT}

Although AAP guidelines recommend global screening twice before the second birthday, adherence appears to be lacking (28). The lack of adherence could be due to the subjectivity within screening, screening tools, or specific knowledge about ASD. In part, this may also be due to the plethora of ASD research focused on the latest up-to-date diagnostic and screening mechanisms. As diagnostic criteria change, assessment tools can become difficult to interpret as they are based on outdated information $(29,35)$. Common screening mechanisms that early interventionist may use to screen ASD include, but are not limited to the modified checklist for autism in toddlers, revised (M-Chat- ${ }^{\mathrm{TM}}$ ) (36), social responsiveness scale (SRS) (37) and the social communication questionnaire (38).

Evidence-based research indicates the use of multiple sources for the diagnosis of $\operatorname{ASD}(31,39)$. This includes, but is not limited to multiple diagnostic tools, developmental assessment, daily living skills as well as clinical judgment. Currently, the "goldstandard" in autism diagnosis consists of the autism diagnostic observation schedule, second edition (ADOS-2) $(7,10,40)$, the autism diagnostic interview-revised (41), and developmental assessments (appropriate for age and level of development at the time of assessment) (29). Additionally, the ADOS-2 and ADI-R have strong interrater reliability as well as strong sensitivity and specificity in the algorithms $(31,42,43)$.

A child can be diagnosed with ASD through an educational diagnosis, using criteria from the Individuals with Disabilities Education Act (IDEA), where the purpose of diagnosis is to indicate if the child qualifies for special education services (44). One limitation to an educational diagnosis is that children have already entered school; therefore, it is "too late" to take advantage of early intervention services. In addition, educational diagnoses have been less aligned with DSM-V criteria; thus, it is possible that some students are missed, within an educational diagnosis. Clinicians and early intervention specialists on the forefront of meeting families and recognizing ASD characteristics in children need to thoughtfully consider best practice in diagnosis and signs that may be present at an early age. 


\section{TREATMENT AND INTERVENTION}

The hallmark characteristics of ASD are deficits in social communication skills as well as repetitive and restricted behaviors (1, 11). For the most part interventions are driven by these hallmark characteristics. For example, interventions have focused on improving social communication skills, such as language skills, play, and reciprocal communication. The necessity of early intervention has been clearly indicated as a priority in autism research $(34,45)$. Findings indicate that children who enter early intervention have a better prognosis $(46,47)$. In 2010, the first randomized clinical control trial of an early intervention for children with autism was published (46). Young pre-school aged children who received this early intervention had improved IQ, language, adaptive behavior, and a better diagnostic prognosis. Other early intervention studies for young children with autism have also had promising results, including but not limited to, better joint attention skills, daily living skills, and ultimately better social and communicative behaviors $(9,33,34,48)$. Amidst this paucity of research promising findings indicate that early intervention has far-reaching positive effects, especially when children enter intervention at a young age. Research about early intervention for children with autism is ongoing, but best practice recommendations suggest: early entry, intensive instruction all day (representative of a school-day) 5-days per week, year-round, and inclusive settings $(45,49,50)$.

Early intervention is a priority of ASD research and consensus among professionals suggests any type of intervention is better than no intervention (34). Current research is testing how intervention types compare to each other to better understand if one modality is better than another. This section reviews widely used intervention strategies - however, it is important to note that many of these intervention methods are continually being assessed for content.

\section{Treatment Modalities}

Treatment modalities for ASD can be divided into three broad categories: psycho-educational or behavioral models, psychopharmacological models, and alternative and complementary models $(51,52)$. This article will discuss some popular behavioral models.

\section{BEHAVIORAL INTERVENTION MODELS}

One of the earliest documented and most widely cited early interventions for young children with ASD is applied behavioral analysis (commonly known as ABA) (53). Positive results from this intensive 40 -h per week behavioral intervention include improvements in intellectual and educational functioning (53). A similar, yet unique early intervention is discrete-trial training (DTT). Proponents of DTT view ASD as a multitude of unique behaviors and reject the idea of one central deficit that can be found in all individuals with ASD.

Discrete-trial training is based on operant-conditioning behavioral models - with reinforcement control as the basis for behavior change. In practice, clinicians and educators use reinforcement, backward chaining, shaping, prompting, and prompt fading to implement DTT. DTT relies on intensive discrete-trial sessions that consist of four parts: (1) the trainer's presentation of stimuli, (2) the child's response, (3) the consequence, and (4) a short pause prior to the next stimuli (54). There are two phases, phase one engages $40 \mathrm{~h}$ per week of one-on-one DTT, administered by trained DTT professionals and the children's parents over a 1- to 2-year period. Phase two focuses on expressive and receptive language skills, abstract play, and social play and uses both DTT and generalization to playgroup and/or supported preschool experiences (55). The behavioral principles of DTT can be successfully applied to children with ASD and the goal is that when placed in environments utilizing DTT, children will emulate typical learning patterns (56). Criticisms of DTT include a loose relationship between the method rationale and the diagnosis of ASD, a narrow approach to language development, the need for "prompt" dependence, and the high cost of the program (57). A controlled study has been conducted and although initial results suggested success, follow-up studies indicated that the learned skills did not improve at a level consistent with peer developmental trajectories (58). Other methodological issues included the lack of random assignment, participant-sampling bias toward higher functioning children with ASD, and assessors who were not blind to study participants (57). In addition, other studies have failed to show similar results to the original controlled study. Yet, DTT is commonly used in practice.

The Pivotal Response Model has no age restriction and has shown effectiveness for increasing positive behavior and decreasing negative behaviors in children of all ages. The literature suggests that the Pivotal Response Model is the most useful in young children, as an early intervention (59). This model is based on the principle that intervention in a few core (or pivotal) areas will increase skills in all areas (even those not directly targeted) and decrease problem behaviors. The pivotal areas include motivation, multiple cues, self-management, and the initiation of social interaction (59). Outcome studies have reported improvements in speech and language, social skills, and generalizing learned skills beyond the treatment setting $(60,61)$.

Treatment and Education of Autistic and related Communication-Handicapped Children (TEACCH) was originally developed for children, but is now used as an intervention at all ages. The overarching goal of TEACCH seeks to work toward participant independence (57). Key principles from the TEACCH model include, careful ongoing assessment, using the strength of the participant as a building block, the use of environment embedded within the behavioral framework and the involvement of parents.

The TEACCH intervention includes diagnosis, parent training, education, social and leisure skills development, communication, vocational training, and supported employment (57). Behavioral strategies include the use of schedules, a visual independent work system, and clearly organized instructional materials to create a structured and predictable learning environment. If children's progress becomes hindered, then the environment is often modified to accommodate the identified issue (62). TEACCH has successfully improved self-help skills, social skills, and communication, enhancing quality of life and reduced inappropriate behavior (63). When children partaking in TEACCH 
were compared with matched peers participating in DTT, the TEACCH children had outcomes three to four times greater than the control group (DTT) on all measures (64). The results of this study should be interpreted with caution as there was no random assignment; therefore, it is hard to draw concrete conclusions between the success of the two programs. Although TEACCH is a widely used intervention strategy, no large, well-controlled study has been conducted to assess its effectiveness $(57,65)$.

The use of Social Stories is a common behavioral intervention in which short, simple stories written from the perspective of the child are used to deliver instruction on appropriate social behavior. These stories are carefully designed to be within the comprehension level of the child and can be used with younger and older children accordingly (66). Although Social Stories are widely accepted due to the connection to prevailing theories of autism, evidence-based research is needed. Case studies as well as other experimental design studies that have been conducted but indicate mixed results. Workshops for parents, teachers, and assistants have been successful toward implementing the use of social stories in the participants' respective environment (67). Other case studies about Social Stories have also displayed mixed results.

The use of visual supports is particularly popular and useful in working with individuals with autism. One such approach is the Picture Exchange Communication System (PECS), which aims to build language skills and teach communication response and initiation (57). Pictures are used to make requests and to form simple sentences. It is a low-cost intervention that does not depend on eye contact or the training of multiple partners, is compatible with TEACCH and the Lovaas method, and works well with pre-verbal or non-verbal children (57).

Many behavioral early interventions consist of specific techniques and require dedicated time by an interventionist or caregiver, often consisting of up-to $40 \mathrm{~h}$ per week of practice. More general best practice recommendations for early intervention include building skills into daily routines, the use of natural environments, and about $25 \mathrm{~h}$ per week of direct skill practice (68). It should be noted that successful early interventions have been indicated with as little as $1 \mathrm{~h}$ per week (69), while more standard practice is about $40 \mathrm{~h}$ per week (56).

\section{A SPECIAL FOCUS ON ASD IN EDUCATIONAL SETTINGS}

\section{Background on Individuals with Disabilities Education Act}

The IDEA passed in 1990 and its successor, the Individuals with Disabilities Education Improvement Act (IDEIA, still referred to as IDEA), was reauthorized in 2004. IDEA protects the rights of children with disabilities and the parents of the children, guarantees that children with disabilities have an appropriate public education adhering to their unique needs, at no cost (Building the Legacy: IDEA 2004, 2010).

Individuals with Disabilities Education Act has its roots in the Education for All Handicapped Children's Act of 1975 (PL 94-148) that provided federal funding to states for free, appropriate public education to children with disabilities. Amendments throughout the 1980s and 1990s added provisions for vocational training and transition services, services, and programs for children birth to age 3 years, transition planning for teenagers, and mandates that schools report children's progress to parents (Building the Legacy: IDEA 2004, 2010) (70). The 2004 reauthorization of the IDEA as well as President George W. Bush's Commission on Excellence in Special Education made attempts to revamp inefficiencies in the special education system.

Individualized Education Plans (IEP) are the foundation of special education services provided to children with disabilities in the public school system. Inclusion requirements for an IEP are mandated at the federal and state level; furthermore, it is mandated that students are educated in the least restricted environment (e.g., students should be placed in general education settings, when the necessary supports are in place and if this meets the needs of the student). Federal requirements consist of a statement of the child's present levels of academic achievements and functional performance, measurable annual goals, a description of benchmarks, a description of how the child's progress toward meeting the annual goals will be measured, and a description of when periodic reports on the progress the child is making toward meeting annual goals will be provided (concurrent with issuance of report cards) (Building the Legacy: IDEA 2004, 2010). When a child turns 16 years of age, the IEP must include a statement of appropriate measurable postsecondary goals related to training, education, employment, and/or independent living skills and a statement of transition services needed to reach those goals. IEPs should allow the child to make progress in the general education curriculum as well as other educational curriculum as needed on an individual basis (Building the Legacy: IDEA 2004, 2010).

\section{ASD, IDEA, and IEPs}

Designing IEPs, specific to individuals with ASD, the objectives, target behaviors, and levels of supports should all be clearly defined, specific, and developmentally appropriate (14). Specific IEP goals should be individualized, but reflective of common characteristics of autism, including communication goals related to requesting, labeling, identifying, following directions, making conversation, using spontaneous and generalized communication skills, greeting, and using and understanding non-verbal communication. Social interaction goals and objectives for an IEP could include joint attention and early social engagement skills, social play, pretend play, consideration of the perspective and feelings of others, friendship, social skills, and problem-solving (14). Lastly, goals and objectives related to restricted and repetitive behaviors could include managing and reducing or eliminating stereotypic behaviors, understanding and demonstrating flexibility, and managing and reducing obsessive thoughts and compulsive behaviors. Other consideration's within IEP goals might reflect behaviors related to emotional self-regulation (mood, anxiety) and behavior management (self-injury, aggression, anger management, staying on-task), academic skills (pre-academic skills, critical thinking, working/being in a group), adaptive skills (feeding, sleeping, dressing, toileting, self-care and self-management, 
functional independent play, daily living skills, participation in family and community, leisure skills, vocational skills, transition to adulthood) (14).

\section{IMPLICATIONS FOR CLINICIANS}

Interventions targeted at social communicative behaviors are necessary for children of all ages diagnosed with autism. Behavioral, personal, and environmental circumstances are all taken into consideration in developing intervention models (69). Early intervention has been particularly targeted due to the positive prognosis indicated through evidence-based research $(9,33$, $34,46)$. There is widespread agreement on the necessity of early intervention but there is less consistent agreement on specific content (34). As little as $6 \mathrm{~h}$ of parent training (didactic group sessions for parents) has been shown to have positive effects on the child's social communicative behaviors $(26,69)$. On the contrary, more than $40 \mathrm{~h}$ of intensive intervention for most waking hours of the child's day has been advocated (53). Standardized diagnostic measures identify children with autism at an early age have been successful $(7,31)$, but providing immediate and effective resources to help families cope with the new diagnosis is lacking (49). Parent-implemented interventions aimed at promoting socialization and communication have had successful results, but

\section{REFERENCES}

1. American Psychological Association (APA). Diagnostic and Statistical Manual of Mental Disorders. 5th ed. Washington, DC: APA (2013).

2. Raines JC. The new IDEA: reflections on the reauthorization for social workers. School Social Work J (2006) 31(1):1-18.

3. Ruble L, McGrew J, Dalrymple N, Jung L. Examining the quality of IEP's for young children with autism. J Autism Dev Disord (2010) 40:1459-70. doi:10.1007/s10803-010-1003-1

4. Center for Disease Control and Prevention (CDC). Prevalence of autism spectrum disorder among children aged 8 years - autism and developmental disabilities monitoring networks, 11 sites, United State, 2010. MMWR Morb Mortal Wkly Rep (2014) 63(SS02):1-21.

5. Previc FH. Prenatal influences on brain dopamine and their relevance to the rising incidence of autism. Med Hypotheses (2007) 68(1):46-60. doi:10.1016/j. mehy.2006.06.041

6. Matson J, Kozlowski AM. The increasing prevalence of autism spectrum disorders. Res Autism Spectr Disord (2011) 5:418-25. doi:10.1016/j.rasd.2010. 06.004

7. Luyster R, Gotham K, Guthrie W, Coffing M, Petrak R, Pierce K, et al. The autism diagnostic observational schedule - Toddler module: a new module of a standardized diagnostic measure of autism spectrum disorders. J Autism Dev Disord (2009) 39:1305-20. doi:10.1007/s10803-009-0746-Z

8. Luyster R, Lord C. Word learning in children with autism spectrum disorders. Dev Psychol (2009) 45(6):1774-86. doi:10.1037/a0016223

9. Kasari C, Gulsrud A, Wong C, Kwon S, Locke J. Randomized controlled caregiver mediated joint engagement intervention for toddlers with autism. J Autism Dev Disord (2010) 40(9):1045-56. doi:10.1007/s10803-0100955-5

10. Lord C, Risi S, Lambrecht L, Cook E, Leventhal B, DiLavore P, et al. The autism diagnostic observation schedule-generic: a standard measure of social and communication deficits associated with the spectrum of autism. J Autism Dev Disord (2000) 30(3):205-23. doi:10.1023/A:1005591205002

11. Kim S, Lord C. Restricted and repetitive behaviors in toddlers and preschoolers with autism spectrum disorders based on the autism diagnostic observation schedule (ADOS). Autism Res (2010) 3:162-73. doi:10.1002/aur.142 more work is needed in order to provide clear instructions and design user-friendly manuals with relevant, easy-to-understand parental resources for families of children with ASD (71). Even though early intervention for some of the youngest children with ASD appear on the forefront of research initiatives, more work is needed to establish effective, meaningful, and parent-friendly intervention techniques (71). Clinicians play a meaningful role in addressing the necessary steps toward active participation in early intervention. Starting with assessment, and finishing with the right intervention "fit" for children and the family.

It is of the utmost importance that clinicians disseminate current research (35). In short, clinicians are most likely to assist children and families in connecting the dots. Clinicians are often the first person, aside from the family, to acknowledge ASD characteristics. Becoming familiar with up-to-date research and better understanding ASD resources within the community will help establish a seamless transition from the clinic to behavioral interventions and further assist families in learning more about how to provide the necessary supports to their child with ASD.

\section{AUTHOR CONTRIBUTIONS}

This manuscript was conceptualized and developed by PA-M; $\mathrm{MM}$ and $\mathrm{KM}$ assisted with manuscript writing.

12. APA. Diagnostic and Statistical Manual of Mental Disorders. 4th ed. Washington, DC: APA (1994).

13. Kurita $\mathrm{H}$. How to deal with transition from pervasive developmental disorder in the DSM-IV to autism spectrum disorder in the DSM-V. Psychiatry Clin Neurosci (2011) 65:609-10. doi:10.1111/j.1440-1819.2011.02268.x

14. Wilczynski SM, Menousek K, Hunter M, Mudgal D. Individualized education programs for youth with autism spectrum disorders. Psychol Schools (2007) 44(7):653. doi:10.1002/pits.20255

15. McPartland J, Coffman M, Pelphrey K. Recent advances in understanding the neural bases of autism spectrum disorder. Curr Opin Pediatr (2011) 23(6):628-32. doi:10.1097/MOP.0b013e32834cb9c9

16. Gurrieri F. Work up autism: the practical role of medical genetics. Am J Med Genet C Semin Med Genet (2012) 160(C):104-10. doi:10.1002/ajmg.c.31326

17. Miles J. Autism spectrum disorders - a genetics review. Genetic Med (2011) 13:278-94. doi:10.1097/GIM.0b013e3181ff67ba

18. Herbert M. Contributions of the environment and environmentally vulnerable physiology to autism spectrum disorder. Curr Opin Neurol (2010) 23:103-10. doi:10.1097/WCO.0b013e328336a01f

19. Betancur C. Etiological heterogeneity in autism spectrum disorders: more than 100 genetic and genomic disorders and still counting. Brain Res (2011) 1380:42-77. doi:10.1016/j.brainres.2010.11.078

20. Baron-Cohen S. The hyper-systemizing, assortative mating theory of autism. Prog Neuropsychopharmacol Biol Psychiatry (2006) 30:865-72. doi:10.1016/j. pnpbp.2006.01.010

21. Chawarska K, Paul R, Klin A, Hannigen S, Dichtel L, Volkmar F. Parental recognition of developmental problems in toddlers with autism spectrum disorders. J Autism Dev Disord (2007) 37(1):62-72. doi:10.1007/s10803-006-0330-8

22. Luyster R, Lopez K, Lord C. Characterizing communicative development in children referred for autism spectrum disorders using the MacArthurBates Communicative Inventory (CDI). J Child Lang (2007) 34(3):623-54. doi:10.1017/S0305000907008094

23. Lloyd M, MacDonald M, Lord C. Motor skills of toddlers with autism spectrum disorders. Autism (2013) 17(2):133-46. doi:10.1177/1362361311402230

24. Staples K, Reid G. Fundamental movement skills and autism spectrum disorders. JAutism Dev Disord (2010) 40(2):209-17. doi:10.1007/ s10803-009-0854-9 
25. Landa R, Gross A, Stuart E, Bauman M. Latent class analysis of early developmental trajectory in baby siblings of children with autism. J Child Psychol Psychiatry (2012) 53(9):986-96. doi:10.1111/j.1469-7610.2012.02558.x

26. Anderson D, Oti R, Lord C, Welch K. Patterns of growth in adaptive social abilities among children with autism spectrum disorders. J Abnorm Child Psychol (2009) 37(7):1019-34. doi:10.1007/s10802-009-9326-0

27. Clinical report: Identification and evaluation of children with autism spectrum disorders. Pediatrics (2007) 120(5):1183-215. Reaffirmed September 2010.

28. Branson D, Vigil D, Bingham A. Community childcare providers' role in the early detection of autism spectrum disorders. Early Child Educ J (2008) 35:523-30. doi:10.1007/s10643-008-0243-6

29. Matson J, Sipes M. Methods of early diagnosis and tracking for autism and pervasive developmental disorder not otherwise specified (PDDNOS). J Dev Phys Disabil (2010) 22:343-58. doi:10.1007/s10882-009-9184-2

30. Zwaigenbaum L, Thurm A, Stone W, Baranek G, Bryson S, Iverson J, et al. Studying the emergence of autism spectrum disorders in high-risk infants: methodological and practical issues. J Autism Dev Disord (2007) 37(3):466-80. doi:10.1007/s10803-006-0179-x

31. Kim S, Lord C. Combining information from multiple sources for the diagnosis of autism spectrum disorders for toddlers and young preschoolers from 12 to 47 months of age. J Child Psychol Psychiatry (2012) 53(2):143-51. doi:10.1111/j.1469-7610.2011.02458.x

32. Ozonoff S, Iosif A, Baguio F, Cook IC, Hill MM, Hutman T, et al. A prospective study of the emergence of early behavioral signs of autism. J Am Acad Child AdolescPsychiatry(2010)49(3):.e1-2.doi:10.1097/00004583-201003000-00009

33. Kasari C, Freeman S, Paparella T. Joint attention and symbolic play in young children with autism: a randomized controlled intervention study. JChild Psychol Psychiatry (2006) 47(6):611-20. doi:10.1111/j.1469-7610.2005.01567.x

34. Kasari C, Freeman S, Paperella T, Wong C, Kwon S, Gultrud A. Early intervention of core deficits in autism. Clin Neuropsychiatry (2005) 2(6):380-8.

35. Heidgerken A, Geffken G, Modi A, Frakey L. A survey of autism knowledge in a health care setting. J Autism Dev Disord (2005) 35(3):323-30. doi:10.1007/ s10803-005-3298-x

36. Robins DL, Casagrande K, Barton M, Chen CMA, Dumont-Mathieu T, Fein D. Validation of the modified checklist for autism in toddlers, revised with follow-up (M-CHAT-R/F). Pediatrics (2014) 133(1):37-45. doi:10.1542/ peds.2013-1813

37. Constantino JN, Gruber CP. Social Responsiveness Scale (SRS). Los Angeles, CA: Western Psychological Services (2007).

38. Rutter M, Bailey A, Lord C. The Social Communication Questionnaire: Manual. Los Angeles, CA: Western Psychological Services (2003).

39. Risi S, Lord C, Gotham K, Corsello C, Chrysler C, Szatmari P, et al. Combining information from multiple sources in the diagnosis of autism spectrum disorders. JAm Acad Child Adolesc Psychiatry (2006) 45(9):1094-103. doi:10.1097/01.chi.0000227880.42780.0e

40. Lord C, Rutter M, DiLavore P, Risi S, Gotham K, Bishop S. Autism Diagnostic Observation Schedule, Second Edition (ADOS-2) Manual (Part 1): Modules 1-4. Torrance, CA: Western Psychological Services (2012).

41. Rutter M, Le Couteur A, Lord C. In: Western Psychological Services, editor. Autism Diagnostic Interview-Revised-WPS. Los Angeles, CA: WPS (2003).

42. Gotham K, Risi S, Pickles A, Lord C. The autism diagnostic observation schedule: revised algorithms for improved validity. JAutism Dev Disord (2007) 37(4):613-27. doi:10.1007/s10803-006-0280-1

43. Gotham K, Pickles A, Lord C. Standardizing ADOS scores for a measure of severity in autism spectrum disorders. JAutism Dev Disord (2009) 39(5):693-705. doi:10.1007/s10803-008-0674-3

44. Noland R, Gabriels R. Screening and identifying children with autism spectrum disorders in the public school system: the development of a model process. J Autism Dev Disord (2004) 34(3):265. doi:10.1023/B:JADD. 0000029549.84385 .44

45. Kasari C, Rotheram-Fuller E. Current trends in psychological research on children with high-functioning autism and Asperger disorder. Curr Opin Psychiatry (2005) 18:497-501. doi:10.1097/01.yco.0000179486.47144.61

46. Dawson G, Rogers S, Munson J, Smith M, Winter J, Greenson J, et al. Randomized, controlled trial of an intervention for infants with autism: the Early Start Denver Model. Pediatrics (2010) 125(1):17-23. doi:10.1542/ peds.2009-0958
47. Sutera S, Pandey J, Esser EL, Rosenthal MA, Wilson LB, Barton M, et al. Predictors of optimal outcome in toddlers diagnosed with autism spectrum disorders. JAutism Dev Disord (2007) 37(1):98-107. doi:10.1007/ s10803-006-0340-6

48. Kasari C, Paparella T, Freeman S, Jahromi L. Language outcome in autism: randomized comparison of joint attention and play interventions. J Consult Clin Psychol (2008) 75(1):125-37. doi:10.1037/0022-006X.76.1.125

49. National Research Council. Educating Children with Autism: Report of the Committee on Educational Interventions in Children with Autism. Washington, DC: National Academy Press (2001).

50. Lord C, Wagner A, Rogers S, Szatmari P, Aman M, Charman T, et al. Challenges in evaluating psychosocial interventions for autistic spectrum disorders. J Autism Dev Disord (2005) 35(6):695-708. doi:10.1007/s10803-005-0017-6

51. Paul H. Review of treating ADHD and comorbid disorders: psychosocial and pharmacological interventions. Child Fam Behav Ther (2011) 33(4):358. doi:10.1080/07317107.2011.623533

52. Greenspan S, Wieder S. Assessing and treating infants and young children with severe difficulties in relating and communicating. In: Greenspan $S$, Kalmanson B, Shahmoon-Shanok R, Wieder S, Williamson G, editors. An Integrated Developmental Approach to Interventions for Young Children with Severe Difficulties in Relating and Communicating. Washington, DC: Zero to Three (1997). p. 5-18.

53. Lovaas O. Behavioral treatment and normal educational and intellectual functioning in young autistic children. J Consult Clin Psychol (1987) 55(1):3-9. doi:10.1037/0022-006X.55.1.3

54. Anderson S, Tara M, O'Malley-Cannon B. Teaching new skills to young children with autism. In: Maurice C, Green C, Luce S, editors. Behavioral Interventions for Young Children with Autism: A Manual for Parents and Professional. Austin, TX: Pro-Ed (1996). p. 181-93.

55. Dawson G, Osterling J. Early intervention in autism: effectiveness and common elements of current approaches. In: Guralnick M, editor. The Effectiveness of Early Intervention: Second Generation Research. Baltimore, MD: P.H. Brookes (1997). p. 307-26.

56. Lovaas O, Smith T. A comprehensive behavior theory of autistic children: paradigm for research and treatment. J Behav Ther Exp Psychiatry (1989) 20:17-29. doi:10.1016/0005-7916(89)90004-9

57. Francis K. Autism interventions: a critical update. Dev Med Child Neurol (2005) 47:493-9. doi:10.1017/S0012162205000952

58. McEachin J, Smith T, Lovaas O. Long-term outcome for children with autism who received early intensive behavioral treatment. Am J Ment Retard (1993) 97(4):359-72.

59. Koegal R, Koegel L, McNerney E. Pivotal areas in intervention for autism. JClin Child Adolesc Psychol (2001) 30(1):19-32. doi:10.1207/S15374424 JCCP3001_4

60. Camarata S, Nelson K. Treatment efficiency as a function of target selection in the remediation of child language disorders. Clin Linguist Phon (1992) 6:167-78. doi:10.3109/02699209208985528

61. Yoder P, Kaiser A, Alpert C, Fischer R. Following the child's lead when teaching nouns to preschoolers with mental retardation. J Speech Hear Res (1993) 36(1):158-67. doi:10.1044/jshr.3601.158

62. Mesibov G, Shea V. Full inclusion and students with autism. JAutism Dev Disord (1996) 26(3):337-46. doi:10.1007/BF02172478

63. Lord C, Schopler E. Stability of assessment results of autistic and non-autistic language-impaired children from preschool years to early school age. J Child Psychol Psychiatry (1989) 30(4):575-90. doi:10.1111/j.1469-7610.1989. tb00269.x

64. Ozonoff S, Cathcart K. Effectiveness of a home program intervention for young children with autism. JAutism Dev Disord (1998) 28(1):25-32. doi:10.1023/A:1026006818310

65. Lord C, Hopkins JM. The social behavior of autistic children with younger and same-age nonhandicapped peers. J Autism Dev Disord (1986) 16(3):249-62. doi:10.1007/BF01531658

66. Scattone D, Wilczynski S, Edwards R, Rabian B. Decreasing disruptive behaviors of children with autism using social stories. J Autism Dev Disord (2002) 32:535-43. doi:10.1023/A:1021250813367

67. Smith C. Using social stories to enhance behavior in children with autistic spectrum difficulties. Educ Psychol Prac (2000) 17(4):337-45. doi:10.1080/02667360120096688 
68. Jennings D, Hanline M, Woods J. Using routines-based interventions in early childhood special education. Dimens Early Child (2012) 40(2):12-23.

69. Vismara LA, Colombi C, Rogers SJ. Can one hour per week of therapy lead to lasting changes in young children with autism? Autism (2009) 13(1):93-115. doi:10.1177/1362361307098516

70. Turnbull H, Wilcox B, Stowe M. A brief overview of special education law with focus on autism. J Autism Dev Disord (2002) 32(5):479-93. doi:10.1023/ A:1020550107880

71. Meadan H, Ostrosky M, Zaghlawan H, Yu S. Promoting the social and communicative behavior of young children with autism spectrum disorders: a review of parent-implemented intervention studies. Topics Early Child Spec Educ (2009) 29(2):90-104. doi:10.1177/0271121409337950
Conflict of Interest Statement: The authors declare that the research was conducted in the absence of any commercial or financial relationships that could be construed as a potential conflict of interest.

The reviewer MS, AB, and handling Editor declared their shared affiliation, and the handling editor states that the process nevertheless met the standards of a fair and objective review.

Copyright (c) 2016 Allen-Meares, MacDonald and McGee. This is an open-access article distributed under the terms of the Creative Commons Attribution License (CC $B Y)$. The use, distribution or reproduction in other forums is permitted, provided the original author(s) or licensor are credited and that the original publication in this journal is cited, in accordance with accepted academic practice. No use, distribution or reproduction is permitted which does not comply with these terms. 